\title{
Declining inequality in schooling in Brazil and its effects on inequality in earnings*
}

\section{David Lam}

University of Michigan, amm Athobr. MI 48109. USA

\section{Deborah Levison}

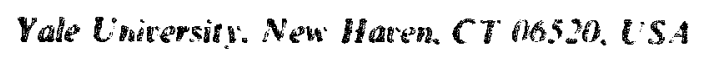

Received November 10g9. Innal version received December 1090

Household survey data demonstrate that Brazilian males born between 1925 and 1963 experienced steady increases in mean schooling and significant declines in schooling inequality. The variance in years of schooling increased for cohorts born up until 1950 , with steady declines for more recent cohorts. Decomposition of a standard human capital earnings equation indicates that trends in schooling tended to reduce earnings inequality from 1976 to 1985 , due to reductions in both the variance of schooling and in returns to schooling. These improvements were more than offset. however, hy increases in other sources of inequality. Although the net increase in earnings inequality from 1976 to 1985 is disturbing, the reduction in schooling inequality represents a fundamental improvement in the determinants of earnings inequality in Brazil that will have beneficial effects for decades.

\section{Introduction}

The relationship between the distribution of years of schooling in a population and the distribution of income has long been a fundamental issue in the literature on income inequality. Numerous studies have estimated the extent to which the distribution of schooling explains earnings i.equality within and across populations, including studies directly linked to human capita! models, such as Becker and Chiswick (1966) and Mincer (1974), and

* An earlier version of this paper was presented at the Annual Bracilin teonomics Mesting. Fortaleza, Brazil, December 1989. This paper has benefited from suggestions by Ricardo Paes de Barros, Guilherme Sedlacek, José Guilherme Almeida dos Reis, and two anonymous referees. Excellent research assistance was provided by Rovrt Shoeni. Support from the Fulbrignt Commission, the Program for International Partnerships of the Universizy of Michigan, and the Instituto de Planejamento Económico a Social - IPEAINPES, Rio de Jazeiro, is grate?ully acknowledged. 
studies pursuing alternative theoretical interpretations, such as Jencks et al. (1972) and Tinbergen (1972).

Research on developing countries has focused particular attention on the issue of how increases in the level of schooling over time affect earnings inequality. A number of authors [e.g. Chiswick (1971), Knight and Sabot (1987), and Marin and Psachoropoulos (1976)] have pointed out that the effect of educational expansion on earnings inequality is difficult to predict a priori, depending on specific changes in different levels of schooling. the relationship between schooling and earnings, and the change in that relationship as schooling increases. Several studies, such as Winegarden (1979), Ram (1984), and Tiiak (1989), have attemptec io clarify the relationship empirically by estimating cross-national regressions of the relationship between income inequality and measures of mean schooling and schooling inequality. These cross-national estimates provide conflicting empirical results, however, and for a variety of reasons give only a limited picture of the relationship between changes in the distribution of schooling and changes in the distribution of earnings over time.

The purposc of this paper is to take a detailed look at the changes in the distribution of schooling in recent decades in one developing country, Brazil, and to analyze the effects of those changes on the distribution of income. Brazil, with its high degree of income inequaiity and relatively low level of schooling in comparison to other countries with comparable levels of per capita income, is particularly appropriate for such a study. In the long debate over income inequality in Brazil, the role of education has frequently been emphasized, as in the well-known studies by Fishlow (1972) and Langoni (1973, 1977). Brazil's educational system is often criticized for producing both low levels of schooling and an unequal distribution of schooling in comparison to countries at similar income levels. There has been little systematic analysis, however, of changes in the distribution of schooling over time either in Brazil or in other deveioping countries.

This paper analyzes changes in the distribution of schooling for Brazilian males born between 1925 and 1963. We show that increases in mean schooling over this period were accompanied by steady decreases in inequality in schooling, as measured by the coefficient of variation and other meaninvariant measures. The variance of years of schooling, an important determinant of earnings inequality, increased along with the mean for cohorts born through the 1940 s, but reached a peak among cohorts born around 1950 and has declined for more recent cohorts.

The relationship between these trends in the distribution of schooling and trends in earnings inequality are analyzed by decomposing a standard human capital earnings equation. The declining variance in years of schooling in and of itself implies a reduction in earnings inequality for more recent cohorts. The relationship is complicated, however. by changes in returns to 
schooling and by other sources of earnings inequality. Comparison of age and cohort proniles of inequality for 1976, 1982, and 1985 shows that earnings inequality in Brazil increased over this period. Based on our decomposition we find that the contribution of schooling was to improve the distribution from 1976 to 1985, with declines in both the variance of schooling and in returns to schooling. Other sources of inequality increased, however, by a magnitude large enough to ofiset the beneficial changes in the distribution of schooling and in the relationship between schooling and earnings.

\section{Changes in the distribution of schooling}

We begin by documerting trends in the distribution of years of completed schooling for three-year birth cohorts of Brazilian males born between 1925 and 1963.' Our analysis is based on the 1985 Pesquisa Nacional por Amostra de Domicilios (PNAD), the annual household survey conducted by Brazil's census bureau, the Instituto Brasileiro de Geografia e Estaristica (IBGE). We divide the sample into three-year age groups in order to follow trends in schooling over recent decades. Given the large sample size of the PNAD, analysis by three-year age groups allows us to have large sample sizes while maintaining relatively fine detail in cohort histories. ${ }^{2}$ We use this nationally representative sample to infer the schooling histories $c i$ birth cohorts from 1925 to 1963 . This will be appropriate if the sample truly represents the national population and if differential effects of mortality and emigration for different schooling groups are negligible for these cohorts.

Table 1 presents summary statistics describing the distribution of sirigle years of completed schooling among three-y.ar age groups in the 1985 PNAD. ${ }^{3}$ The steady increase in the mean level of completad schooling for Brazilian males can be seen in column (4) of table 1 and in fig. 1. Although the level of schooling remains low, the mean years of completed schooling for Brazilian males has increased steadily over time, doubling over the four decades included here. Mean years of schoolinig rose from three years for the 1925-27 cohort to six years for the 1961-63 cohort. The most rapid increase in the mean occurred for the cohorts born from 1940 to 1954, most of whom attended school during the $1950 \mathrm{~s}$ and early 1960s. The pace of the

\footnotetext{
${ }^{1}$ Because we are interested in the distribution of income as well as schooling. Wollow most of the literature on earnings and inequality by restricting our attention to males, avoiding the more diffcult labor supply issues involved in analysis of female life cyce earnings.

${ }^{2}$ We have a sample of over 100,000 males in the cohorts being analyzed. With the smallest three-year age group containing over 2,800 observations.

${ }^{3}$ The results reported use the sample weights provided by IBGE to produce a representatve sample of individuals for the Brazilian population. Sample sizes repured refer to the unweighted number of observations. All statistics are calculated using the sample weights. The algorithm used to construct the variable for single years of schooling is available from the authors on request.
} 
Table 1

Years of completed schooling for three-year age groups - Brazilian males. 1985 PNAD

\begin{tabular}{|c|c|c|c|c|c|c|c|c|c|}
\hline \multirow{2}{*}{$\begin{array}{l}\text { Age } \\
\text { group } \\
\text { (1) }\end{array}$} & \multirow{2}{*}{$\begin{array}{l}\text { Birth } \\
\text { cohort } \\
\text { (2) } \\
\end{array}$} & \multirow{2}{*}{$\begin{array}{l}\text { Sample } \\
\text { size } \\
\text { (3) }\end{array}$} & \multirow[b]{2}{*}{$\begin{array}{l}\text { Mean } \\
\text { (4) }\end{array}$} & \multirow[b]{2}{*}{$\begin{array}{l}\text { Variants } \\
(5)\end{array}$} & \multirow{2}{*}{$\begin{array}{l}\text { Coefl of } \\
\text { variation } \\
\text { (6) }\end{array}$} & \multicolumn{4}{|c|}{ Percent complating } \\
\hline & & & & & & $\begin{array}{l}\text { 0 Years } \\
\text { (7) }\end{array}$ & $\begin{array}{l}4+\text { Ycars } \\
\text { (8) }\end{array}$ & $\begin{array}{l}8+\text { Years } \\
\text { (9) }\end{array}$ & $\begin{array}{l}11+\text { Years } \\
1101\end{array}$ \\
\hline $22-74$ & $1961-63$ & 13,937 & 5.98 & 16.08 & 0.67 & 11.8 & 722 & 37.8 & 200 \\
\hline $25-27$ & $1958-60$ & 13,024 & 5.93 & 17.80 & 0.71 & 12 & 70.9 & 36.4 & 209 \\
\hline $28-30$ & $1955-57$ & 11.734 & 5.89 & 19.33 & 0.75 & 13.2 & 70.2 & 349 & 21.8 \\
\hline $31-33$ & $1952-54$ & 10.622 & 5.77 & 20.66 & 0.79 & 14. & 670 & 329 & 216 \\
\hline $34-36$ & $1949-51$ & 9.643 & 5.24 & 21.00 & 0.87 & 17.9 & 61.3 & 28.4 & 18.8 \\
\hline $37-39$ & $1946-48$ & 8,386 & 4.95 & 20.84 & 0.92 & 19.1 & 578 & 25.4 & 169 \\
\hline $40-42$ & $1943-45$ & 7,634 & 4.43 & 19.12 & 0.99 & 23.4 & 52.5 & 210 & 14.3 \\
\hline $43-45$ & $1940-42$ & 7.123 & 4.08 & 17.79 & 1.03 & 25.2 & 48.2 & 189 & 12.5 \\
\hline $46-48$ & $1937-39$ & 6,109 & 3.92 & 16.75 & 1.04 & 26.5 & 47.6 & 17.7 & 11.3 \\
\hline $49-51$ & $1934-36$ & 5,588 & 3.78 & 16.52 & 1.08 & 28.2 & 46.1 & 167 & $\ln 8$ \\
\hline $52-54$ & $1931-33$ & 4,942 & 3.58 & 15.70 & 1.11 & 30.7 & 44.3 & 15.5 & 100 \\
\hline $55-57$ & $1928-30$ & 4.590 & 3.32 & 14.84 & 1.16 & 33.7 & 40.9 & 179 & 8.6 \\
\hline $58-60$ & $1925-27$ & 4.099 & 3.05 & 14.03 & $i .23$ & 37.3 & .977 & 12.3 & 7.7 \\
\hline $22-60$ & $1925-63$ & 107.431 & 4.98 & 19.11 & 0.88 & 19.6 & 59.3 & 27.2 & 16.8 \\
\hline
\end{tabular}

increase in the mean appears to have slowed beginning with the 1955-57 cohort, although incomplete schooling for the youngest cohorts may partially explain this levelling-off.

The variance in years of schooling for the same group of male cohorts is shown in column (5) of table 1 . We will focus on the variance extensively below, since it will be shown to be a fundamental variable in our decomposition of earnings inequality, For expositional convenicnce we plot the standard deviation of years of schooling in fig. 1, since it is meas"red in units comparable to the mean. As the table and figure demonstrate, the standard deviation rises from the 1925-27 cchort to the 1949 51 cohort, then declines for cohorts born in the 1950s and 1960s. This peak in the variance in years of schooling was previously noted in Lam and Levison (1990), using data from the 1976 PNAD. It is more firmly established here using the 1985 data, since the 1949-51 cohort was 34-36 years of age at the time of the 1985 survey, old enough that acquisition of schooling should have been virtually complete. The peak in the variance of schooling will be a permanent characteristic of the distribution of schooling during the lifetime of the 194951 cohort, and has important impications for the distribution of earnings.

Fig. 1 also demonstrater an important feature of the change in meanadjusted schooling inequality. Although the standard deviation in years of schooling increased over time for cohorts born between 1925 and 1948, it

\footnotetext{
${ }^{4}$ If schooling is incomplete for the younger cohorts. the variance in years of schooling will be understated for those cohorts. Comparison of the same cohoris in other years suggests that the peak in the variance of schooling is not simply an artifact of this effect, as will be discussed further below.
} 


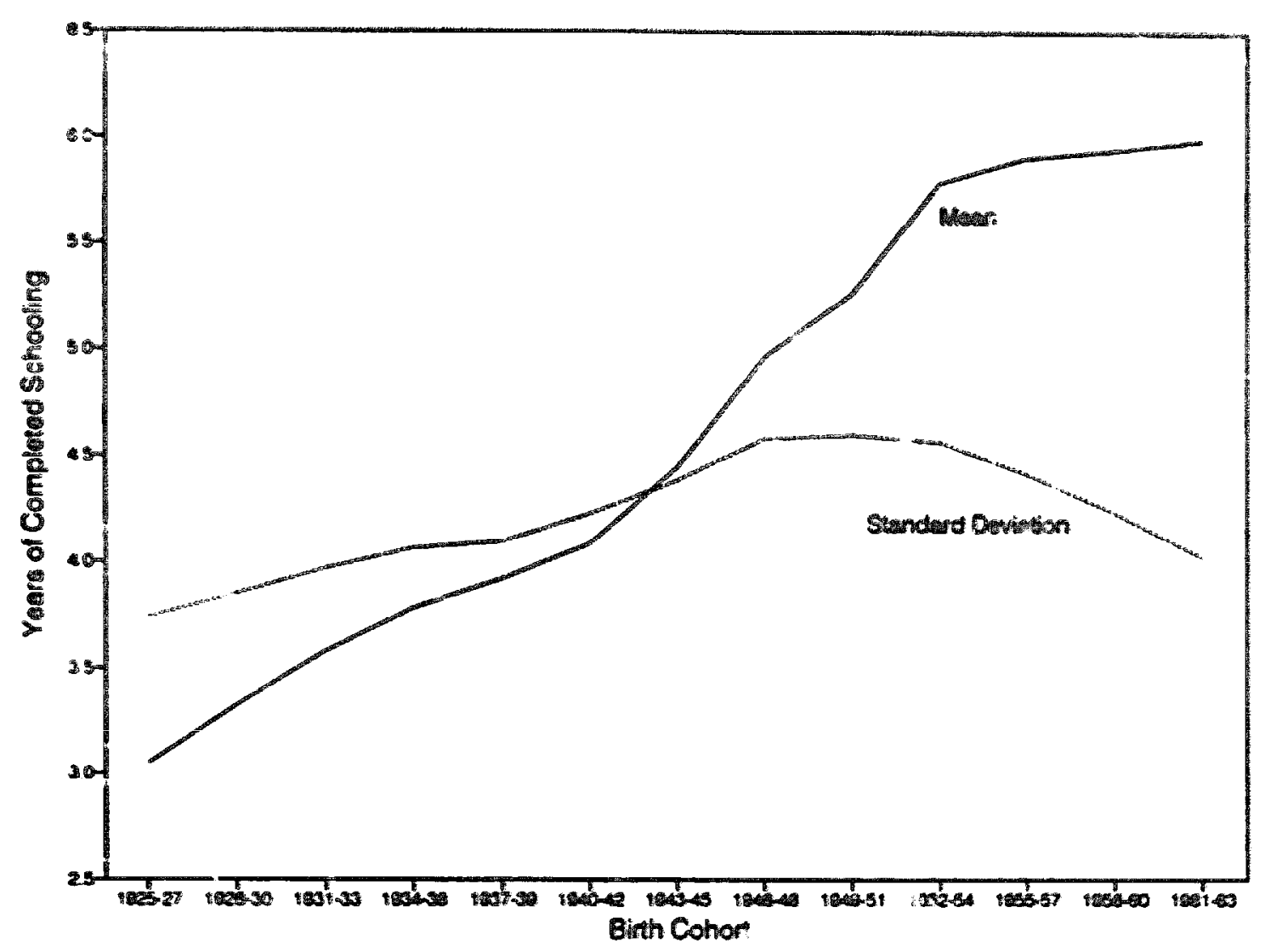

Fig. 1. Years of completed schooling. mean and standard deviation: Three-year birth cohorts. Brazilian males. PNAD 1985.

never increased as fast as the mean, as it would have if there had been proportional increases in schooling throughout the population. This implies that the coefficient of variation. a standard inequality measure that is independent of the mean, declined steadily during the four decades under consideration. The coefficient of variation (the standard deviation divided by the meani is shown in eribm. (6) of table 1. By this measure, inequality in schooling for Brazilian males has decined steadily in recent decades. Whille mean schooling has doubled. the coeficient of variation has been almost sut in half. 5

This pattern of a rising mean and falling coefficient of variation is not unique to Brazil. Psacharopoulos and Arriagada (1986) present estimates of the proportion of the labor force with iarivis lcicls of schooling, along with an estimate of mean schooling, for a large number uf sumities. Datia ate reported for more than one year for iwenty countries. Räbit $(1990)$ uses the

\footnotetext{
${ }^{5}$ Lam and Sedlacek 1990 , using the same data. document a similar pattern for Brazilian women. Mean shooling for women rose from 2.7 years for the $1925-27$ cohori. eve-sidily surpassing males to reach a ievel of 6.3 years for the 1962-63 cohort. Females exhbir a peak in the variance of schooling with the 1952-54 cohort. slighty later than that fy men.
} 
grouped data to estimate the standard deviation for each population. Although these numbers are only roughly comparable to ours, since they apply to the entire labor force rather than to specific cohorts, and since they are based on categorical frequency distributions rather than the single-year of schooling data we use, it is possible to compare changes over ten- to twentyyear intervals in means, standard deviations, and coefficients of variation. Among these twenty countries, Brazil has one of the largest increases in mean schooling, both absolutely and proportionately, with somewhat slower growth than that of Korea, but faster growth than most other Asian countries and most Latin American countries. In all twenty countries mean schooling rose at a faster rate than the standard deviation, implying reductions in mean-adjusted inequality in schooling in all cases. ${ }^{6}$

One important component of the rising mean in the years of schooling in Brazil is the falling proportion with zero years of completed schooling, shown in column (7) of table 1 . The percentage of males with no schooling has declined steadily, falling from 37 percent for the 1925-27 cohort to under 12 percent for the 1961-63 cohort. Columns (8), (9), and (10) of table 1 show other important points in the cumulative distribution. The proportion with at least four years has increased from 38 percent to 73 percent, the proportion with at least eight years (completion of primary school) has increased from 12 percent to 38 percent, and the proportion with at least eleven years (completion of high school), has increased from 8 percent to 20 percent. The fact that the proportion with high school education appears tc have declined for the most recent cohorts suggests that incomplete schooling may complicate results for the younger cohorts, an issue discussed further below.

A more complete picture of the changes in the distribution of schooling is provided by comparing the single year frequency distributions for three particular cohorts: 1925-27, the oldest cohort in table 1; 1949-51, the cohort with the highest variance in schooling; and 1961-63, the youngest cohort in table 1. Fig. 2 plots the frequency distribution of years of schooling for these three cohorts. The basic shapes of these densities are quite similar, with peaks at zero, four, eight, and eleven years, consistent with completion of levels of the Brazilian schooling system. The most striking difference between the oldest and youngest cohorts is the sharp decline in the proportion with

\footnotetext{
${ }^{6}$ Ram (1990) ases the standard deviation as his measure of schooling inequality, rejecting mean-adjusted measures such as the coefficient variation because, among other reasons, they do not equal zero when the mean is zero. Ram's critention is an odd one, since most inequality measures satisfying standard axioms will violate it. We usc the variance of schooling in our decompositions of earnings inequality below, but follow the conventional literature on income inequality by maintaining the conceptual distinction between changes in means and changes in mean-adjusted dispersion, using the term 'inequality' to refer to measures that are independent of the mean. We also follow previous iteraluie on scheoling inequality, such as the classic study by Jencks (1972), who uses the coefficient of variation as a measure of schooling inequality.
} 


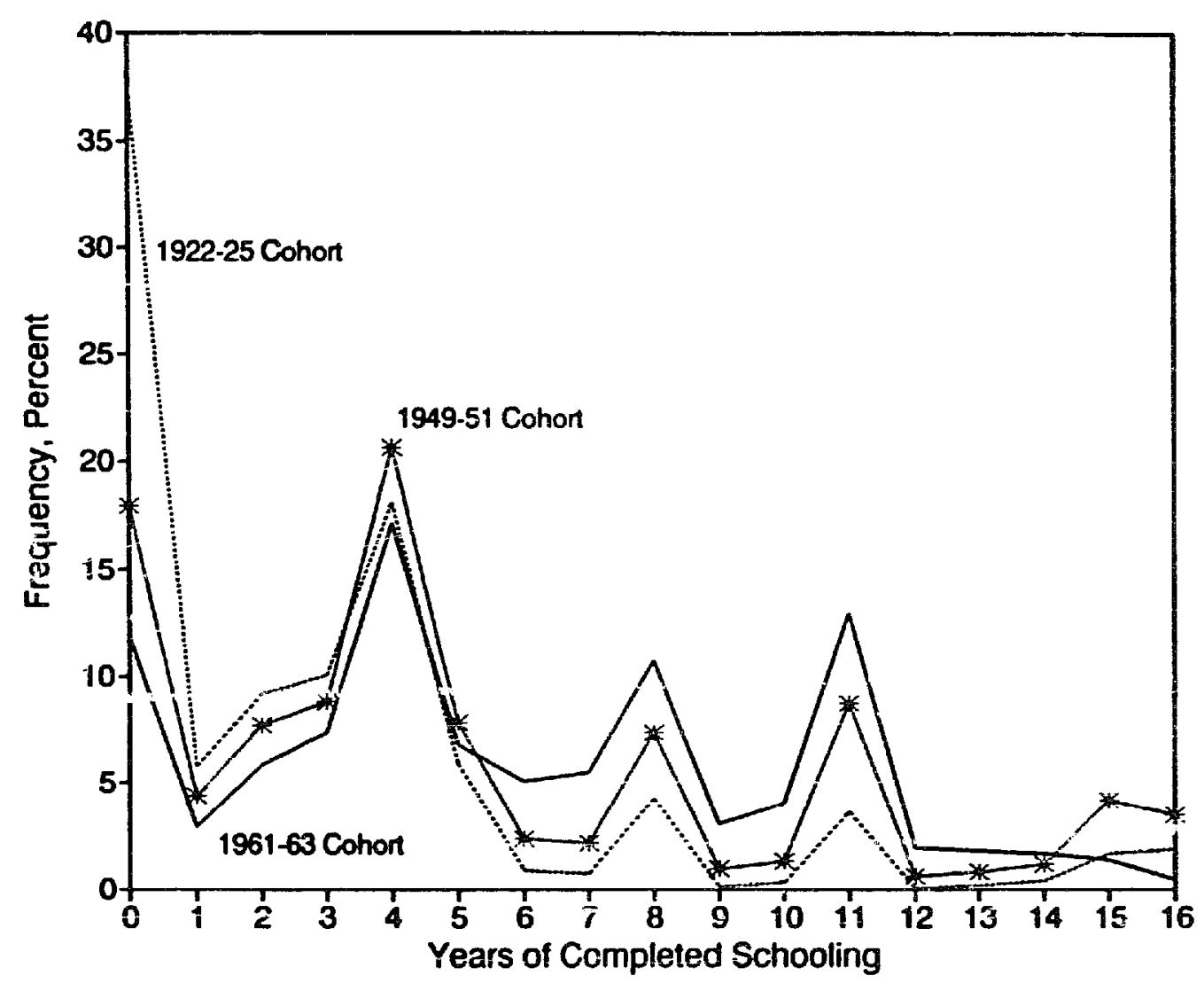

Fig. 2 Freguency distrihution, years of completed schouling: 1925-2?, 1949-51, and :96!-6? birth cohorts, Brazilian males, PNAD 1985.

zcro schooling. The proportion earning exactly four years is remarkably constant across the three cohorts. This should not be interpreted as indicating inertia in the distribution of schooling, however. Fig. 2 demonstrates that all levels of schooling under four years have become less prevalent over time while levels of schooling over four years have become more prevalent, with four years being roughly the point at which the densities intersect.

The cumulative schooling distributions implied by the densities in fig. 2 , and shown in the last four columns of table 1 , come very close to indicating first-order stochastic dominance in the distributions over time, she condition that would be implied if the cumulative distributions did not iniersect. An instructive way to interpret these distributions is to imagine utility defined as a function of years of schooling: $U(S)$. Given a utiiiarian social welfare function $\int U(S) f(S) \mathrm{d} S$, first-order stochastic dominance implies nigner social welfare for any function $U(S)$ that is increasing in $S$. Thus, first-order stochastic dominance would imply that the distribution of schooling in Brazil has unambiguously improved over time. It is even stronger than second- 
order stochastic dominance, which would imply higher social welfare for any concave function $U(S)$ [see Atkinson (1970), Kakwani (1980), Shorrocks (1983), and Lam (1988)]. As can be seen from the last four columns of table 1 , there is close to unambiguous improvement in the schooling distributions by the criterion of first-order stochastic dominance for every cohort in comparison to the cohorts preceding it.

The cumulative distributions imply unaniviguous improvements in the distribution of schooling across cohorts of Brazilian males, using the same criteria of stochastic dominance used for comparing non-mean-adjusted income distributions [Shorrocks (1983)]. Much of this improvement results from increases in the mean. In comparing income distributions, it is standard practice to also consider mean-adjusted measures of dispersion which abstract from the mean level of income. In the same spirit, it is instructive to consider whether inequality in schooling, abstracting from the mean, has declined over time in Brazil. We have already seen that one standard inequality measure, the coefficient of variation, does in fact decline steadily over the period we consider. A more complete comparison can be made by analyzing Lorenz curves for the distribution of schooling, defined - analogously to Lorenz curves for income - as the cumulative proportion of years of schooling plotted against the cumulative proportion of the population.

Fig. 3 shows Lerenz curves for years of schooling for the same three cohorts analyzed above. The ligure shows that the Lorenz curve for schooling shifts unambiguously upward over time, implying unambiguous improvements in schooling equality. For example, the least educated fifty percent of the porulation in the 1925-27 birth cohort had less than eight percent of the twiat years of schooling of that cohort. For the 1961-63 birth cohort, the least educated fifty percent had 23 percent of the total years of schooling. The Loicnž cuirves indicate that the share of years of schooling accounted for by those at the bottom of the distribution has risen steadily over time.

Analysis of Lorenz curves for the distribution of schooling is unusual, but it follows naturally from any analysis of schooling inequality. ${ }^{7}$ To interpret these Lorenz curves, consider the relationship between Lorenz curves for the distribution of schooling and Lorenz curves for the distribution of income. From the literature on Lorenz curves and social welfare we know that Lorenz dominance in incume implies higher social welfare for any concave utility function, abstracting from changes in the mean [Atkinson (1970), Shorrocks (1983)]. Mapping from schooling to utility through income, $U[Y(S)]$, Lorenz dominance in schooling implies unambiguously higher

\footnotetext{
${ }^{7}$ Jencks et al. (1972), in fact, presents what amount to points on Lorenz curves for schooling across birth cohorts in his classic study of schooling inequality and earnings inequality in the United States
} 


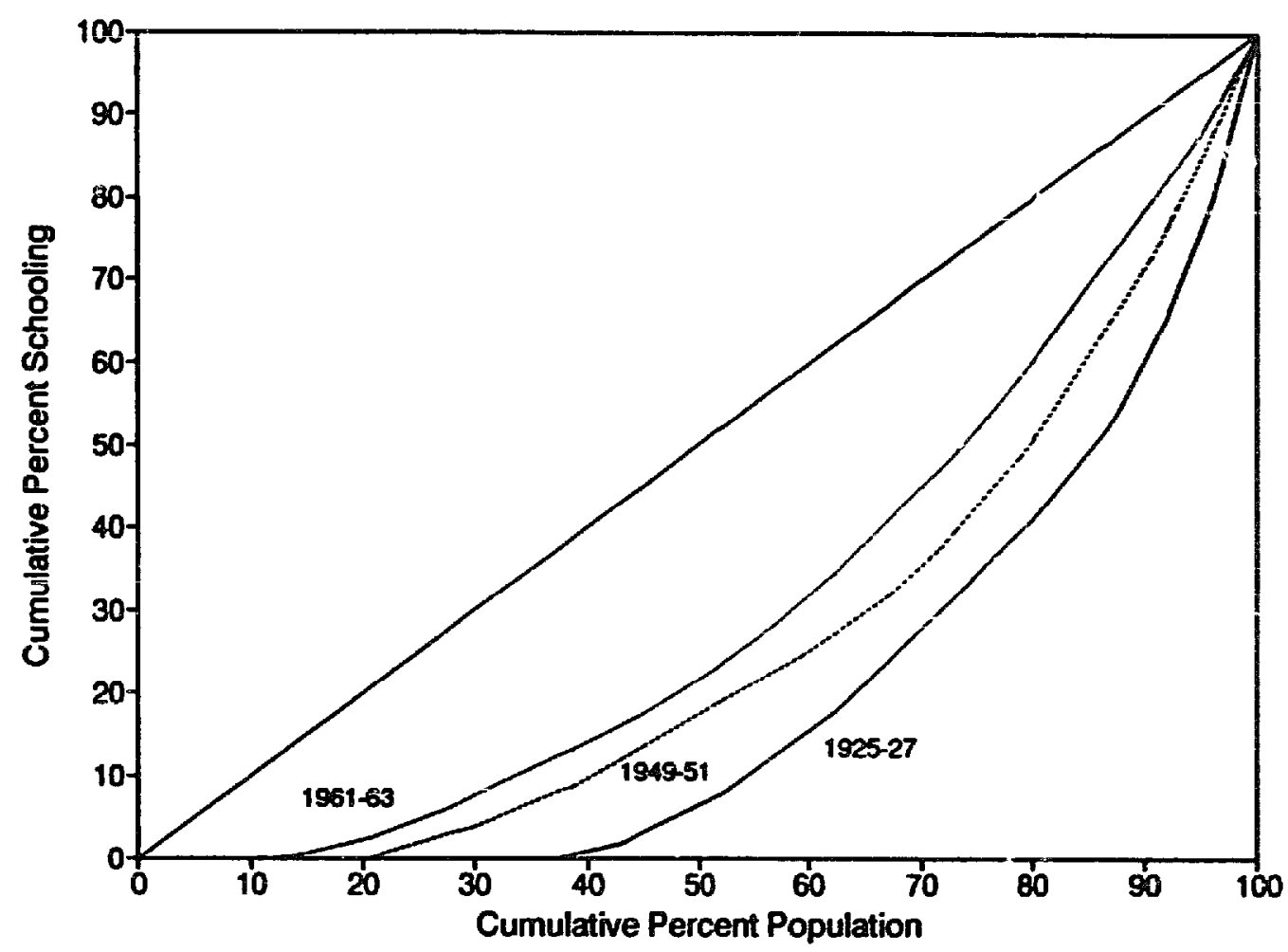

Fig. 3. Lorenz curves, years of completed schooling: 1925-27, 1949-51, and 1961-63 birth cohorts, Brazilian males, PNAD 1985.

social welfare, even with no increase in mean schooling, if utility is a concave function of schooling. Sufficiont (but not necessary) conditions for utility to be a concave function of schooling are (i) that income is a concave function of schooling and (ii) that utility is a concave function of income. While these conditions sound plausible at first, it is noteworthy that income is actually a convex function of income in the most standard representation, the conventional log-linear human capital earnings equation: $\ln Y=\alpha+\beta S$. An implication of this functional relationship is that we may observe an unambiguously more equal distribution of schooling, as indicated by Lorenz dominance in schooling distributions, accompanied by an unambiguously less equal distribution of earnings, as indicated by Lorenz curves for earnings, even if schooling completely determines earnings. It will be seen below that the unambiguous improvements in mean-adjusted inequality in schooling in Brazil did not necessarily imply improvements in the distribution of earnings in Brazil during the period in which the variance in years of schooling was increasing.

\section{Implications for the distribution of income}

The changes in the distritution of schooling documented above could be 
expected to have important implications for the distribution of earnings. The link between schooling and the distribution of income has been emphasized in the literature on income inequality. Predictions based on a human capital model were made by Becker and Chiswick (1966) and Chiswick (1971), including a prediction that decreasing inequality in schooling would lead to decreasing inequality in earnings. Empirical tests based on cross-national data provide mixed evidence. ${ }^{8}$ Winegarden (1979) found mean schooling negatively associated with income inequality, and the variance of schooling positively associated with income inequality based on data for 32 countries. Ram (1984) found only marginally significant effects based on data for 28 countries, with the variance of schooling having an equalizing, rather than disequalizing, effect. As emphasized by Knight and Sabot (1987), rising mean levels of education can in principle either increase or decrease earnings inequality, depending on the specific changes in different levels of schooling and on the relationship between schooling and earnings. As we will see below in the case of a human capital earnings equation, it is possible to generate decreases in inequality in schooling simultaneously with increases in inequality in earnings.

One natural way to link the distribution of schooling to the distribution of earnings is in the context of a simple conventional earnings equation,

$$
\ln Y_{i}=\alpha+\beta S_{i}+u_{i}
$$

where $\ln Y_{i}$ is the natural logarithm of the $i$ th individual's labor earnings, $S_{i}$ is the ith individual's year of schooling, and $u_{i}$ is a residual representing all other determinants of the ith individual's earnings. We omit experience from the earnings equation, since for narrow age groups a standard experience proxy will be almost perfectly correlated with ycars of schooling. Eq. (1) can be thought of simply as an empirically appropriate functional form or can be motivated by a human capital model of earnings, as in Mincer (1974). Whatever the motivation, specify ing eq. (1) in the conventional semi-log form means that it provides an analytically simple decomposition of the variance of log earnings, a standard measure of inequality. ${ }^{9}$

Assuming that $\alpha$ and $\beta$ represent constants across the population, the variance of $\log$ earnings $V(\ln Y)$ implied by eq. (1) is

$$
V(\ln Y)=\beta^{2} V(S)+V(u)+2 \beta C(S, u),
$$

\footnotetext{
${ }^{8}$ See Tilak (1989) for a recent survey of this literature.

${ }^{9}$ In addition to the fact that use of the variance in log earnings follows naturally from the human capital earnings equation. it is a videly used inequaliqy mesusure. li saitifies most standard axioms for inequality measures and among the class of conventional measures gives relatively more weight to the bottom of the distribution [see Kakwasti (1980), and Atkinson (1970)].
} 
where $V(S)$ is the variance in years of schooling, $V(u)$ is the variance in components of earnings uncorrelated with schooling, and $C(S, u)$ is the covariance between schooling and variables omitted from the earnings equation.

According to eq. (2), the variance of years of schooling is a fundamental determinant of the variance in log earnings. If schooling is uncorrelated with other determinants of earnings not included in the simple earnings eq. (1), then changes in the variance of schooling lead directly to changes in earnings inequality by a factor that is the square of returns to schooling. If returns to schooling are constant and 'residual variance' is constant, then earnings inequality, as measured by the log variance, is simply a linear function of the variance in years of schooling.

Eq. (2) implies that it is possible for earnings inequality to increase at the same time that schooling inequality is declining. According to the equation, inequality in earnings is a function only of the variance in years of schooling, with no independent effect of mean schooling. But inequality in schooling, as conventionally defined, is a function of both the variance and the mean. If the variance in schooling rises while the coefficient of variation in schooling falls, then we will observe an increase in earnings inequality at the same time as a decrease in schooling inequality. This is exactly the situation that applies to cohorts of Brazilian males born between 1925 and 1951. Although successive cohorts had declining inequality in schooling by all mean adjusted measures of inequality, we would expect them to have increasing earnings inequality because of the increase in the variance in schooling over this pericd. For cohorts bom after 1951 bosh mean-aujjusted inequality in schooling and the variance in schooling declined, implying declining inequality in earnings.

We will use eq. (1) as the basis for analyzing the relationship between the distribution of schooling and the distribution of earnings. We will adopt a human capital interpretation of eq. (1), but recognize that the estimate of $\beta$ may capture effects other than strictly private returns tc schooling. Correlations between schooling and omitted variables will not only affect interpretation of the coefficient on schooling, but imply that the final term in eq. (2) cannot be ignored in decomposing the variance of log earnings. Changes in the distribution of schooling may in such a case affect the variance in log Eaminings not only through the 'explained variance', $\beta^{2} V(S)$, but also through 'unexplained variance".

Although our primary interest is not in estimates of returns to schooling per se, the appropriateness of the specification of earnirigs eq. (1) does affect the interpretation of our results. If returns to schooling are nonlinear, for example, then the variance in log earnings will depend on higher moments of the schooling distribution beyond the variance. If a guaciatis term belongs in the earnings equation, then it is not precisely accurate to interpret the 
'explained variance' from estimation of eq. (1) as capturing all effects of the distribution of schooling. While the explained variance captures all effects on income that are correlated with schooling, it will not capture higher-order effects that would show up, for example, as correlations between income and schooling squared. We use the specification in eq. (2) because it provides an analytically simple decomposition of age-specific inequality. The addition of simply a quadratic schooling term, for example, would add two additional components to the decomposition, one depending on the kurtosis of the schooling distribution, and one depending on the skewness. While such a decomposition might be instructive, we believe the linear decomposition captures the most important components of the relationship between schooling inequality and earnings inequality. ${ }^{10}$

An additional assumption implicit in our intrepretation of the decomposition in eq. (2) is that there are constant returns to schooling within any cohort. We thus omit one of the determinants of earnings inequality in the theoretical decomposition of Becker and Chiswick (1966) and Chiswick (1971), the variance in returns to schooling. Given variance in returns to schooling, a rising mean level of schooling will tend to increase earnings inequality even if the variance in years of schooling is constant. Our results shouid also bc qualified by well-known warnings that the coefficient on schooling includes the effects of many omitted variables correlated with schooling. It is often argued that in Brazil, as in many developing countries, high levels of schooling are more concentrated among the children of wealthy families than they are in the U.S., so that schooling may partly serve as $a$ proxy for status and family connections. Identifying the precise meaning of the strong association between schooling and earnings in Brazil is beyond the scope of this paper, but we note that caution should be used in applying a strist human capital interpretation to the results. ${ }^{11}$

\section{Earnings equations and the decomposition of earnings inequality, 1985}

In order to analyze the relationship between the distribution of schooling and the cistribution of earnings for the cohorts discussed above we present estimates of earnings eq. (1) for separate three-year age groups of Brazilian

\footnotetext{
${ }^{10} \mathrm{As}$ will be demonstrated below in discussing the robustness of our results, the simple linear specification is in fact a surprisingly good fit for the separate three-year age groups we use for oue regressions.

${ }^{11}$ We also recognize that we are abstracting from many historical and institutional determinants of inequality, particularly in regard to the large regional variations in inequality in Brazil. We have repeated our analysis for separate regions of Brazil and for rural and urbañ samples. These results are reported in Lam and Levison (1989) and are summarized briefly below.
} 
Table 2

Monthly labor earnings by years of age: Descriptive statistics and age-specific earnings equations, Brazilian males with positive earnings, 1985 PNAD."

\begin{tabular}{|c|c|c|c|c|c|c|c|c|c|c|}
\hline \multirow[b]{2}{*}{$\begin{array}{l}\text { Age } \\
\text { group } \\
\text { (1) } \\
\end{array}$} & \multirow[b]{2}{*}{$\begin{array}{l}\text { Birth } \\
\text { cohort } \\
\text { (2) }\end{array}$} & \multirow[b]{2}{*}{$\begin{array}{l}\text { Sample } \\
\text { size } \\
\text { (3) }\end{array}$} & \multirow{2}{*}{$\begin{array}{l}\text { Mean } \\
\text { earnings } \\
(\mathrm{x} .000) \\
(4)\end{array}$} & \multirow{2}{*}{$\begin{array}{l}\text { Mean } \\
\text { log } \\
\text { earnings } \\
(5)\end{array}$} & \multirow{2}{*}{$\begin{array}{l}\text { Variance } \\
\text { log } \\
\text { earnings } \\
(6)\end{array}$} & \multicolumn{5}{|c|}{ Age-specific earnings equation } \\
\hline & & & & & & $\begin{array}{l}\hat{\beta} \\
\text { (7) }\end{array}$ & $\begin{array}{l}\text { Std. err. } \\
\text { (8) }\end{array}$ & $\begin{array}{l}R^{2} \\
(9)\end{array}$ & $\begin{array}{l}V(u) \\
(10)\end{array}$ & $\begin{array}{l}\hat{\beta}^{2} V(S) \\
(11)\end{array}$ \\
\hline $22-24$ & 1961-63 & 11,689 & & & 0.638 & 0.110 & & 0.296 & 0.449 & 0.189 \\
\hline $25-27$ & $1958-$ & 11,76 & 1,080 & & & & & & & \\
\hline $28-30$ & $1955-57$ & 10,956 & 1,330 & 13. & 0.865 & 0.13 & 0.00 & & 514 & 352 \\
\hline $31-33$ & $1952-54$ & 10,022 & 1,572 & 13.75 & 0.987 & 0.147 & 0.0016 & 0455 & 0.538 & 0.449 \\
\hline $34-36$ & $1949-51$ & 9,152 & 1,6 & & 1.0 & 0.1 & & 0.478 & 0.556 & 0.509 \\
\hline $37-39$ & & & & & & & nn & 0.469 & 0.598 & 0.528 \\
\hline & & 157 & 1,7 & 13. & & 0.163 & & 0.469 & 0.585 & 0.518 \\
\hline & & & & & & & & & 0.608 & 0.487 \\
\hline $46-4$ & $1937-39$ & & & & & & & 0.416 & 0.651 & 0.463 \\
\hline $45-j i$ & 193426 & 4,788 & 1,584 & 13. & 1.1 & 0.164 & 0.002 & 0.401 & 0.673 & 0.450 \\
\hline $52-54$ & $1931-33$ & 3,982 & 1,5 & 13. & 1.09 & 0.165 & 0.0033 & 0.388 & 0.672 & 0.425 \\
\hline $55-57$ & $1928-30$ & 3,463 & 1,3 & 13. & & 0.1 & 0.0 & 0.3 & 0.727 & 0.380 \\
\hline $58-60$ & $1925-27$ & 2,841 & 1,334 & 13.38 & 1.156 & 0.171 & 0.0045 & 0.341 & 0.762 & 0.394 \\
\hline $22-60$ & $1925-63$ & 95,794 & 1,424 & 13.61 & 0.998 & 0.138 & 0.0006 & 0.370 & 0.629 & 0.370 \\
\hline
\end{tabular}

a'Earnings' refers to local earnings in cruzeiros from all jobs in the month prior to the survey (September 1985). Figures for mean earnings in column (4) are divided by 1,000. Regression results are for OLS regression in $Y_{i}=x+\beta S_{i}$ for each age group.

niales with positive monthly earnings in the 1985 PNAD. These regressions, along with descriptive statistics for earnings, are presented in table $2^{12}$

For graphical analysis of the results in table 2 we can use either year of birth or age as the unit of reference. While the choice is at one level simply a question of whether to read the table from top to bottom or bottom to top, it draws attention to more fundamental conceptual issues in analyzing earnings inequality across age groups. The mean and standard deviation of schooling, plotted in fig. 1 as a function of year by birth, could appropriately be thought of as properties of cohorts. That is, they vary by age for adults in a single cross-section because of changes in schooling over time, not because of a fundamental relationship between schooling and age. Labor earnings, on the other hand, vary systematically with age, and could be thought of as a function of age rather than cohort. We graph the components of earnings as a function of age in the following figures, recognizing that what we see is a

\footnotetext{
${ }^{12}$ Changing from the sample of all Brazilian males to the sample of Brazilian males vith postive labor earnings causes some changes in the distribution of schooling. The differences in the two samples depend on the age group. At younger ages the sample of working males has slightly higher mean schooling than all males, while at older ages the sample of working males is slightly less educated than the sample of all males. The differences are modest. however, and do not cause any significant changes in the patterns of mean and variance of schooling across cohorts documented above.
} 
combination of 'age' and 'cohort' effects, with the relative impor tance of the two components varying from graph to graph.

Fig. 4 shows the variance in lng earnings for each age group, along with the explained and unexplained components of this variance implied by our estimates of eq. (1) for each age group. The shape of the age profile of inequality has important implications for the relationship between the age composition of the population and the overall distribution of income. ${ }^{13}$ As shown in fig. 4 and in column (6) of table 2, the variance of $\log$ earnings for Brazilian males rises steeply from age group 22-24 to age group 37-39, then is relatively flat for older ages. The relationship between age and inequality shown in fig. 4 is similar to the pattern estimated by Langoni (1973) for separate age groups of Brazilian males using the 1970 census. The pattern differs significantly from the relationship between age and earnings inequality in the United States: Mincer (1974), Schultz (1975), and Smith and Welch (1979) all find U-shaped profiles of incquality by age in cross-section estimates for U.S. males. ${ }^{14}$ As discussed in more detail in Lam and Levison (1990), the shape of this age profile of inequality is a result of interactions between the cohort profile of variance in schooling, changes in returns to schooling by age, and the age profile of residual varianse.

The increase in inequality from age group 22-24 to age group 37-39 in fig. 4 is consistent with our predictions based on the cohort profile of the variance in schooling documented above. The increase in inequality with age suggests that the declining variance in schooling across cohorts is causing the decline in inequality in earnings for more recent cohorts. The explanation for the age profile of inequality is in fact more complicated, however. As we will see below, changes in the varianse of schooling across cohorts are only one part of the explanation for the relationship between age and inequality in Brazil.

Returning to eq. (2), we note that an important determinant of the variance in log earnings is the returns to schooling. ${ }^{15}$ Column 7 of table 2 indicates that estimated returns to schooling vary significantly as a function of age in Brazil, rising steeply from age group 22-24 to age group 40-42, then remaining relatively flat at higher ages. ${ }^{16}$ Both age and cohort factors may play a role in determining this profile. Knight and Sabot (1981), for example, suggest that higher levels of schooling for younger cohorts may

\footnotetext{
13See, for example, Paglin (1975), Morley (1981) and Lam (1984).

it The profile of earnings inequality bv experience has also been estimated by a number of researchers. See Lam and Levison (1990) for a discussion of this literature and comparisons of age and experience profiles of inequaing in Brazil and the U.S.

${ }^{15}$ Overall, estimated returns to schooling for males aged 22-60 are 0.138 in 1985. This is close to Senna's (1976) estimates of 0.125 and 0.127 for Brazilian males, using the same simple earnings function and a 1970 Ministry of Laboi survey.

${ }^{16}$ tandard ?rors are consistently very small, and the estimates of returns to schooling are, without exception, significant at the one percent level.
} 


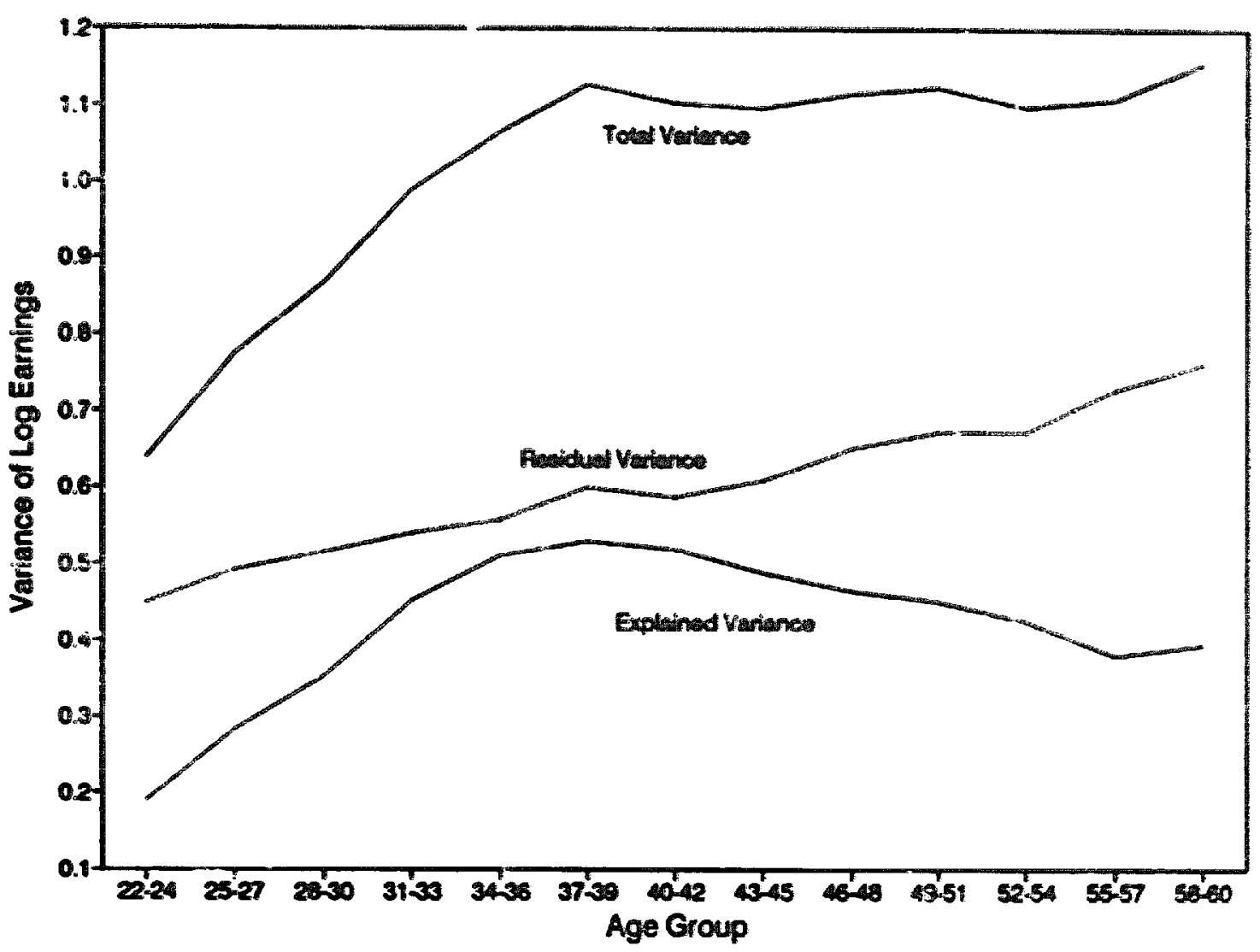

Fig. 4. Earnings inequality. three-year age groups: Total variance of log earnings, explained variance. and residual variance. males with positive earnings, all Brazil. PNAD 1985.

explain the frequently observed increase in returns to schooling with age. Comparisons with estimates from the 1976 and 1982 PNADs, presented below, reveal a very similarly shaped age profile, however, suggesting that there is some persistent systematic relationship between age and returns to schooling in Brazil.

Returns to schooling combine with the variance in years of schooling to account for the 'explained variance' in earnings inequality, $\beta^{2} V(S)$, in eq. (2). Column 10 of table 2 and fig. 4 show this explained variance from the earnings regressions for three-year age groups. The explained variance is highest for men ages 37-39, representing cohorts born in 1946-48. The two elements of this explained variance behave very differentiy in the degree to which they are 'age' or 'cohort' driven. The variance of schooling is primarily a charactristic of cohorts, remaining constant once a colont is beyond about age 25. As shown above, the variance of schooling is highest for the 1949-51 cohort, corresponding to the 34-36 age group in 1985. Theoretical arguments could be made ior both age and cohort effects in relums so schooling, especially in a population experiencing rapid changes in the level of 
schooling. Whatever the explanation for the age pattern in returns to schooling, it interacts with the cohort pattern in variance of schooling to produce the relationship between age and 'explained variance' shown in fig. 4.

The residual (unexplained) variance in the age-specific earnings equations is shown in column (9) of table 2 and in fig. 4. Residual variance rises fairly steadiily irom age $i \bar{y}-\overline{2} \dot{1}$, increasing from 0.45 for the youngest cohort to 0.76 for the oldest cohort. This residual variance includes variance resulting from post-schooling investments in human capital, such as on-the-job training and experience, as emphasized by Mincer (1974). It may also pick up effects of changes in schooling to the extent that schooling is correlated with variables omitted from the simple log-linear earnings eq. (1). In any case, from an accounting perspective, it is an important explanation of the fact that inequality increases with age for Brazilian males.

\section{Changes in earnings inequality, 1976-1982-1985}

Have the improvements in the distribution of schooling in Brazil documented above led to improvements in the distribution of earnings? In this section we compare the earnings distributions for 1976, 1982, and 1985 in order to document the changes in earnings inequality over this period and to identify the role of schooling in those changes. ${ }^{17}$ In comparing income distributions across periods, a fundamental problem of identification exists. If we compare the same age group in different periods, different cohorts are being compared. If we compare the same cohort in different periods, we are capturing the cohort at different points in the life cycle. Thus cohort effects will appear to be period effects when we control for age, and age effects will appear to be period effects when we control for cohort. Figs. 5 and 6 demonstrate the problem in comparing income distributions across time in Brazil.

Fig. 5 shows the variance in log earnings for three-year age groups of Brazilian males using the 1976, 1982, and 1985 PNADs. The figure shows that inequality is higher for every age group in 1985 than in 1982, and is higher in 1985 than in 1976 for all age groups above 34. Fig. 6 plots the same data as a function of birth cohort rather than age. ${ }^{18}$ Every birth cohort has higher earnings inequality in 1985 than in 1982 and 1976. Every birth cohort except that of 1925-27 has higher earnings inequality in 1982 than in 1976.

In spite of the impressive improvements in the distribution of schooiing,

\footnotetext{
${ }^{17}$ In making this comparison we are assuming that the PNAD surveys for these three years ar $r^{-}$consistently representative of the national population. The validity of this assumption is dis cussec below.

${ }^{8}$ The cohort figures include only the observations for age groups greater than 21 years of age.
} 


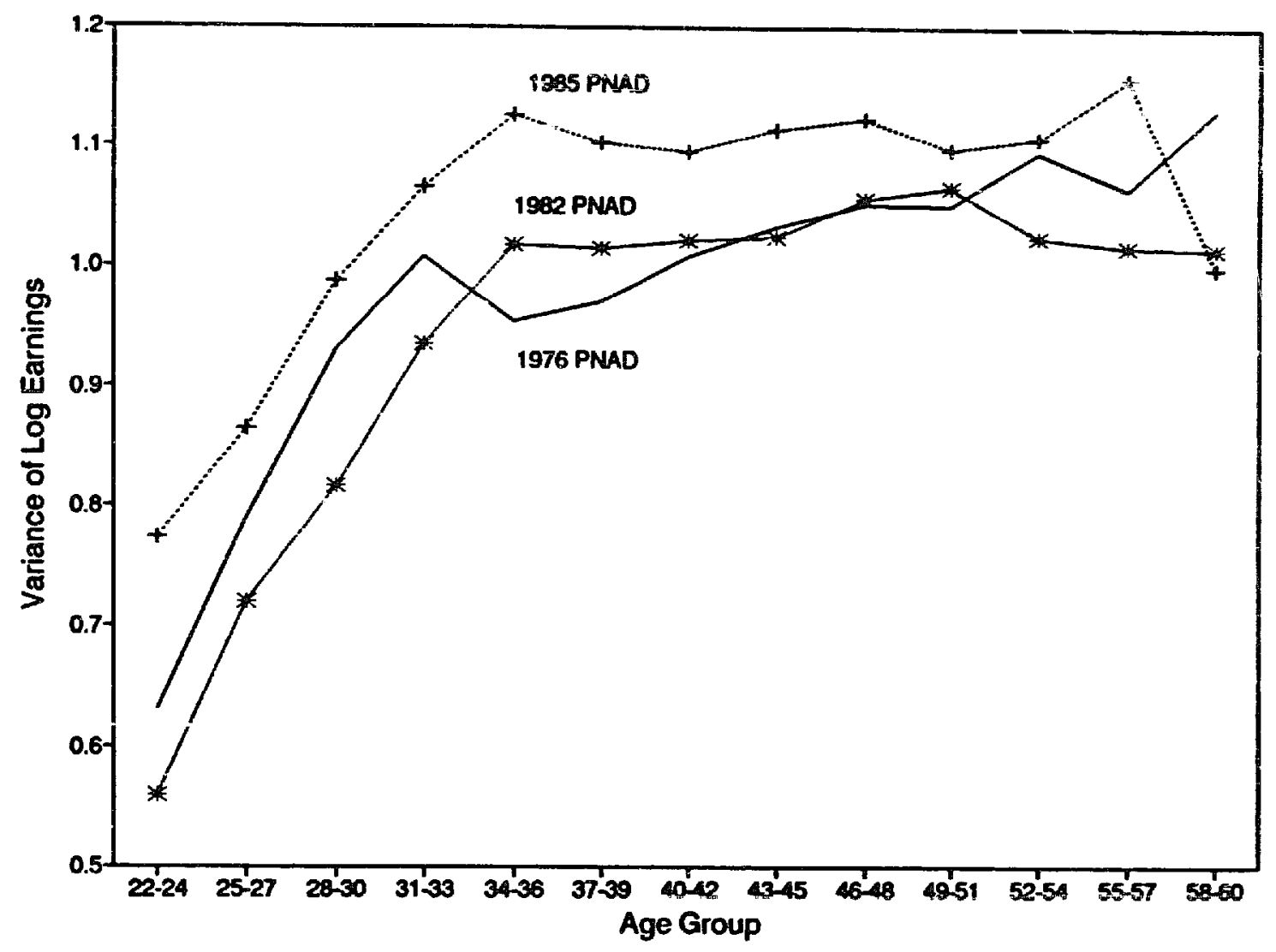

Fig. 5. Variance in log earnings for three-year age groups: Brazilian maies with positive earnings, PNAD 1976-1982-1985.

the fact that earnings inequality increased for every birth cohort and most age groups from 1976 to 1985 shows that the distribution of earnings was worsening. What is the explanation for this disturbing increase in inequality, and how do we reconcile it with the improvements in the distribution of schooling? Once again, a decomposition of earnings inequality is instructive.

\subsection{Changes in the distribution of schooling}

Looking first at fig. 5, what is the explanation for the increase in inequality for every age group from 1982 to 1985 and for older age groups from 1976 to 1985? An important part of the explanation is a cohort effect for older age groups resulting from the changing distribution of schooling over lime. This cohort effect is completely independent of changing economic conditions, and thus should not be attributed to differences in the Brazilian economy in 1976 , 1982, and 1985. An instructive example is provided by the 37-39 year age group in fig. 5 , an age group which shows large changes in inequality across the three periods. This age group corresponds to the $1944-48$ birth colnon in 


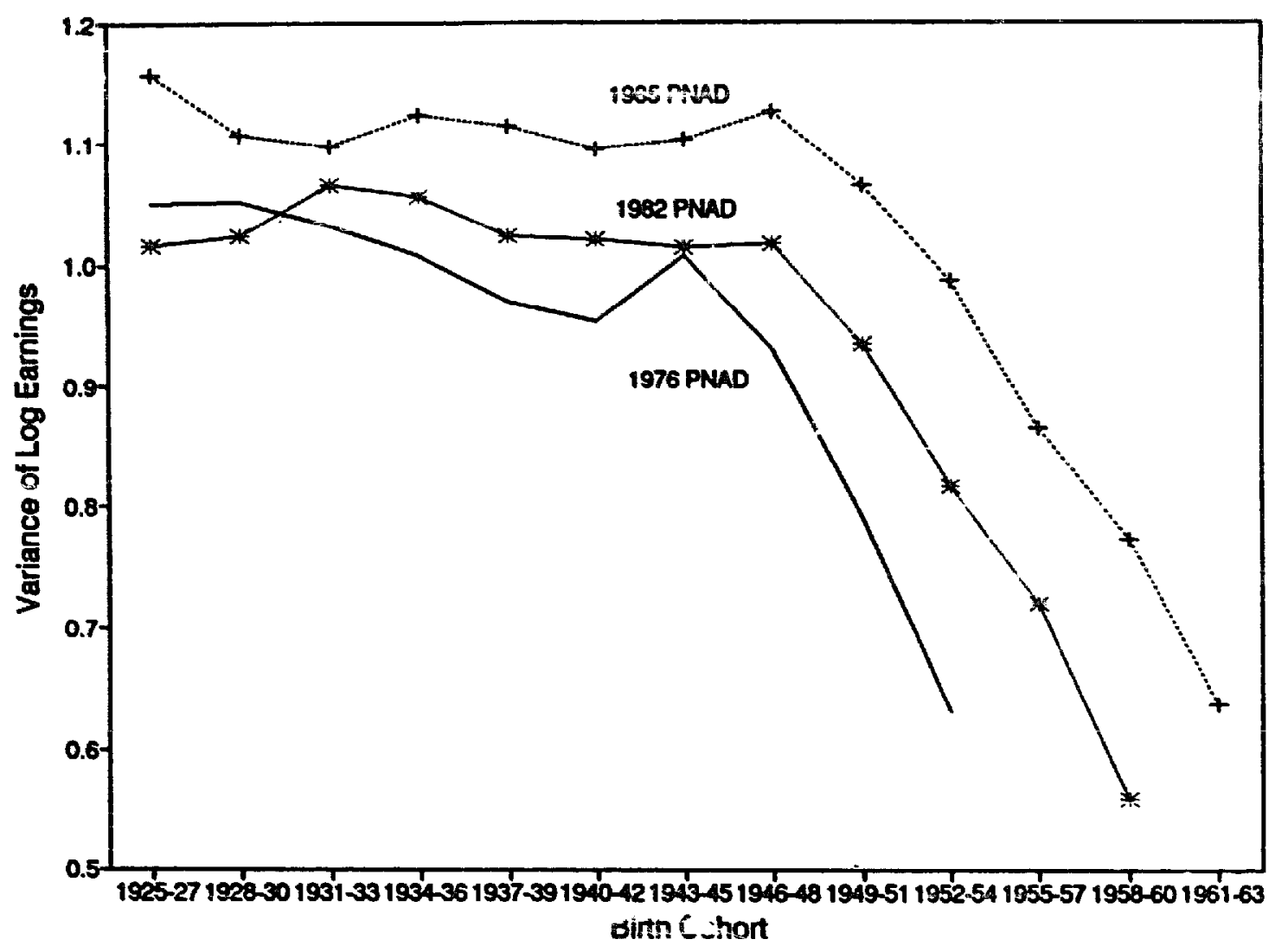

Fig. 6. Variance in log earnings for three-year birth cohorts: Brazilian males with positive earnings, PNAD 1976-1982-1985.

1985, the 1943-45 birth cohort in 1982, and the 1937-39 birth cohort in 1976. Looking back at table 1 , we see that these three cohorts had very different variances in years of schooling. The large differences in earnings inequality for this age group in the three periods are primarily attributable to the changes in the variance of schooling over time, without necessarily implying anything about the economic conditions of the three periods.

We thus see how the changes in the distribution of schooling in Brazil can affect the distribution of income over time. In the case of the three survey years being compared here, this cohort effect is disequalizing for oider age groups and equalizing for younger ones. For older ages, the birth cohort at a given age in 1985 had a higher variance of schooling than the birth cohort at that same age in 1982. This is true for cohorts born before the peak in the variance in schooling. For younger ages, the birth cohort at a given age in 1985 should have had a lower variance of schooling than the birth cohort at that age in 1982.

The problem of potentially misleading cohort effects shown in fig. 5 can be avoided by comparing cohorts over time rather than age groups. Fig. 6 
compares earnings inequality in 1976, 1982, and 1985 for the same birth cohorts. Since the variance of schooling should remain constant for a cohort over time, the increases in inequality for birth cohorts shown in fig. 6 cannot be attributed to changes in the variance of schooling. The comparisons across cohorts in fig. 5 introduce another source of potentially misleading inference, however. The changes in earnings inequality over time for a given birth cohort will be affected by changes in either returns to schooling or residual variance as a function of age. From the results presented above w: know that both returns to schooling and residual variance vary significantly with age in Brazil. We therefore look at each of these variables for 1976, 1982, and 1985 to investigate their possible role in explaining the increase in earnings inequality in Brazil during this period.

\subsection{Changes in returns to schooling}

As emphasized above, one of the critical factors affecting changes in inequality across periods is changes in returns to schooling. Langoni (1973) emphasized the role of changes in returns to schooling in explaining apparent increases in inequality in Brazil during the 1960s and 1970s. Langoni argued that inequality increased in that period partly because of an increase in returns to schooling, a result of quasi-rents to human capital caus od by Brazil's rapid (and presumably unexpected) economic growth.

Fig. 7 shows returns to schooling for each three-year age group in 1976, 1982, and 1985, based on estimates of earnings equations of the form of eq. (1). The figure shows that returns to schooling fell over time for every age group, a decline which in and of itself should imply a decline in earnings inequality for every age group over the period. In the case of older age groups, the decline in returns to schooling tends to offset the increase in inequality resulting from the fact that cohorts with higher variance in schooling moved into those age groups in 1985. For younger age groups the decline in returns to schooling reinforces the decrease in inequality resulting from the fact that cohorts with lower variance in schooling moved into those age groups in 1985 .

The decline in returns to schooling at every age group in Brazil during this period is noteworthy, although we cannot be certain if it represents longterm trends or short-run period effects. Trends in the overall level of returns to schooling will be an important determinant of long-term trends in earnings inequality in Brazil. Like many other developing countries, Brazil has typically had much higher estimated returns to schooling than the United States and other industrialized economies [see Psacharopoulos (1981) and Schultz (1988)]. Lam and Levison (1990), for example, find that the estimated returns to schooling for Brazilian males are hicher by around five 


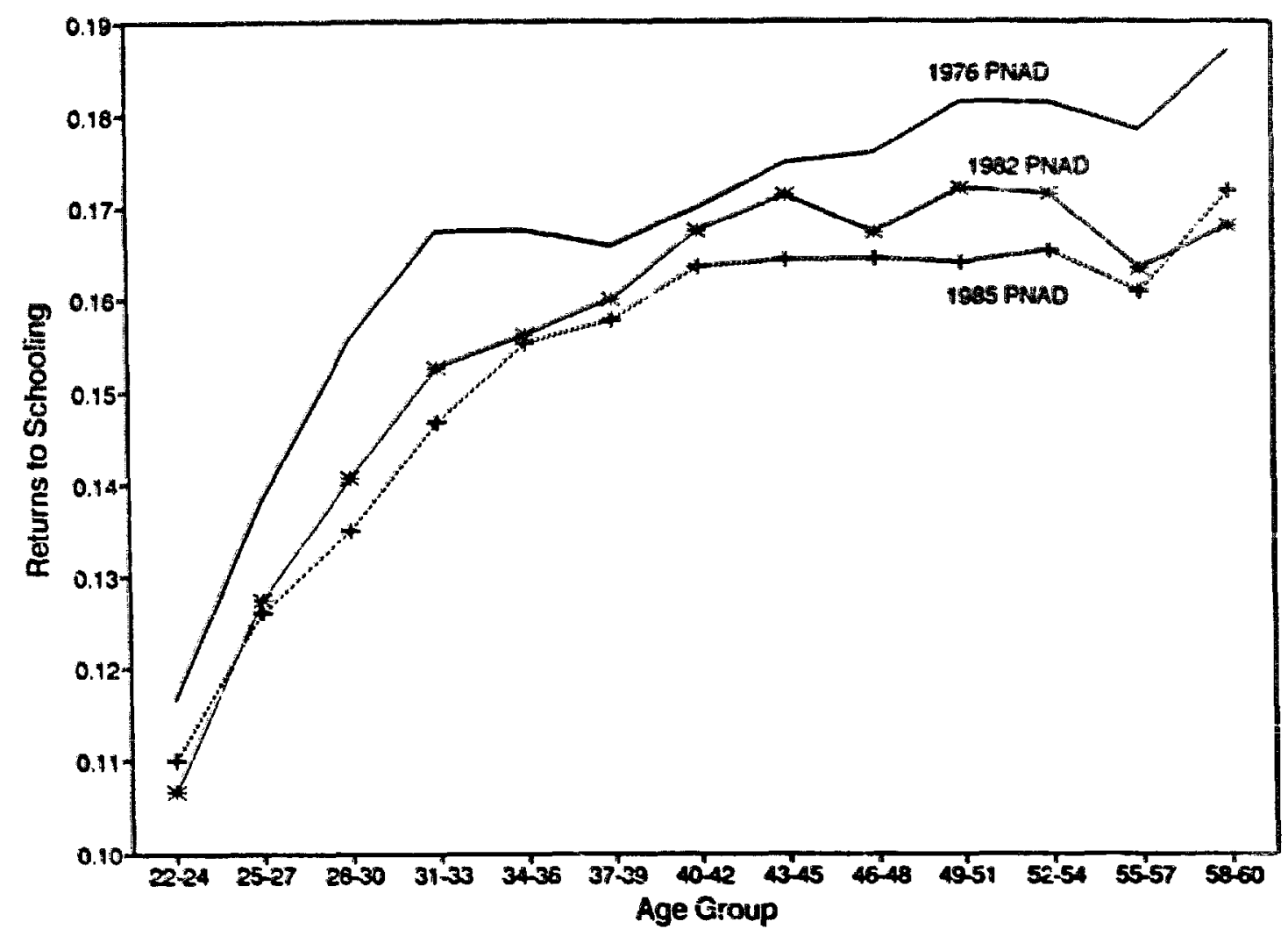

Fig. 7. Estimated returns to schooling for three-year age groups: Brazilian maies with positive earnings, PNAD 1976-1982-1985.

percentage points than returns to schooling for males in the United States for almost every age group.

The decline in returns to schooling in Brazil for every age group between 1976 and 1985 may indicate that the increasing mean level of schooling in Brazil is leading to a dissipation of high rents to what has in the past been relatively scarce human capital. If this is true it implies that earnings inequality should diminish over time as increasingly better educated birth cohorts enter the labor force. Whether the decline in returns to schooling shown in fig. 7 is a permanent trend or a result of short-run cyclical conditions in the Brazilian economy in the three years shown, ${ }^{19}$ it remains true that this decline had an equalizing effect over this period.

\subsection{Residual varinnre}

Since our estimates indicate that there was both a decrease in the variance

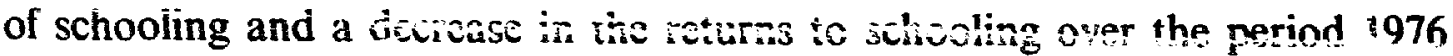

\footnotetext{
${ }^{19}$ In 1976 economic conditions were declining after the honm years of 1968-74; the recassion bottomed out in 1982-83, and conditions were on the upswing in 1985 .
} 
to 1985 , the overall increase in inequality between 1976 and 1985 shum in fig. 5 and fig. 6 is not attributable to schooling, at least in the accounting implied by the decomposition of eq. (2). The con:tribution of schooling to inequality over this period was to improve the cistribution of income. It follows that changes in residual variance, the variance in the components of earnings uncorrelated with schooling, must play an important role. Table A.I in the appendix details the elements of the inequality decomposition for 1976 and 1982, paralleling table 2's breakdown for 1985. A comparison of residval variance for age groups and birth cohorts. based on the estimation of earnings eq. (2) for 1976, 1982, and 1985, shows that residual variance is higher for every age group and for every birth cohort in 1985 than in 1982 and 1976. Changes in residual variance from 1976 to 1982 are less clear. Although there is a small increase in inequality for most birth cohorts from 1976 to 1982, this is primarily the result of the strong tendency for residual variance to increase with age in Brazil. In fact, every age group but one had lower residual variance in $\mathbf{1 9 8 2}$ than in 1976.

The overall increase in residual variance from 1976 to 1985 for both age groups and birth cohorts is large enough to overcome the equalizing effects of declining variance in years of schooling and declining returns to schooling. This is disturbing, since it implies that Brazil failed to experience the improvements in the distribution of income that should have resulted from changes in the distribution of schooling and the returns to schocling. On the other hand, to the extent that residual variance as we measure it i.e. the variance in the components of earnings that are uncorrelated with schooling) is being driven by short-term cyclical effects, including perhaps the rate of inflation. it may be reassuring that the increase in inequality from 1976 to 1985 can be attributed to residual variance. The equalizing effects of the improved distribution of schooling represent a fundamental change in the determinants of earnings inequality in Brazil. This schooling component of inequality wiil persisi for decades in Brazil. The fact that succeeding cohorts of Brazilian males have continually lower variance in years of schonling will in and of itself improve the distribution of earnings in the future. As the cohorts who experienced the highest variance in schooling, those born around 1950, move through the age distribution and are replaced by more recent cohorts, overall inequality in Brazil should begin to demonstrate the kind of improvements that can now only be seen by looking at narrow age groups.

\section{Robustness of the results}

The results presented above are potentially sensitive to a number of assumptions. If the 1985 PNAD survey does not accurately represent the national population of Brazil, then cohort-type aralysis based on this cross- 
section will be misleading, affecting our conclusions about changes in the distribution of schooling over time. If some men in younger cohorts have not completed schooling at the time of the 1985 survey, the observed decline in the variance of schosiling may be an artifact of incomplete schooling. If the 1976, 1982, and 1985 PNAD surveys are not consistent with each other, then our con:lusions about changes in returns to schooliing over time may be unreliable. Misspecification of the earnings equation is another concern, since it could affect the validity of the returns to schooling estimates and the interpretation of our decomposition. In this section, we provide a brief examination of these issues.

Comparison of the schooling distribution for the same cohorts across different sampie years provides evidence on both the consisiency of the PNAD samples and on the potential effects of incomplete schooling for younger men. The 1976. 1982, and 1985 samples provide quite consistent estimates of mean schooling across cohorts once cohorts reach their midthirties. Discrepancies between mean schooling for the same cohorts in 1982 and 1985 are typically less than one-tenth of a year, a quantity that is onethird to one-half as large as the change in mean scinooling from one threeyear age group to the next. The 1976 sample is somewhat less consistent, with means of the order of 0.3 to 0.4 years below those of 1985 for almost ail cohorts. Comparisons of the variance in schooling suggest that incomplete schooling does contribute to falling variances for younger cohorts. The observed peak in variance appears to be real, however. The 1946-48 cohort has the highest schooling variance in both the 1976 and 1982 samples, changing to the flat peak across the 1946-48 and 1949-51 cohorts in the 1985 sample, documented in fig. 1. We conclude from our comparisons that the 1982 and 1985 samples are highly consistent, suggesting that the assumption that they provide a consistent sample of the national Brazilian population is reasonable. We are somewhat less confident of the comparability with the 1976 survey, although it provides a very similar picture of the basic patterns in both the mean and variance of schooling. It appears clear that there has been at least a substantial flattening of the variance in years of schooling across cohorts, with fairly compelling evidence that the variance has been declining for cohorts born since the early fifties.

In orier to test the robustness of our assumption of a linear specification of the earnings equation, we used the 1985 data to estimate more flexible specifications. Our sample sizes are large enough for most age groups io allow us to estimate regressions using eighteen dummy variables for the individual years of schooling. In addition to testing the robustness of our linearity assumption, these estimates are interesting in their own right for the picture they provide of the relationship between schooling and earnings in Brazil. Fig. 8 shows the results for three representative age groups. The coefficients show log earnings for each schooling level relative to men with 


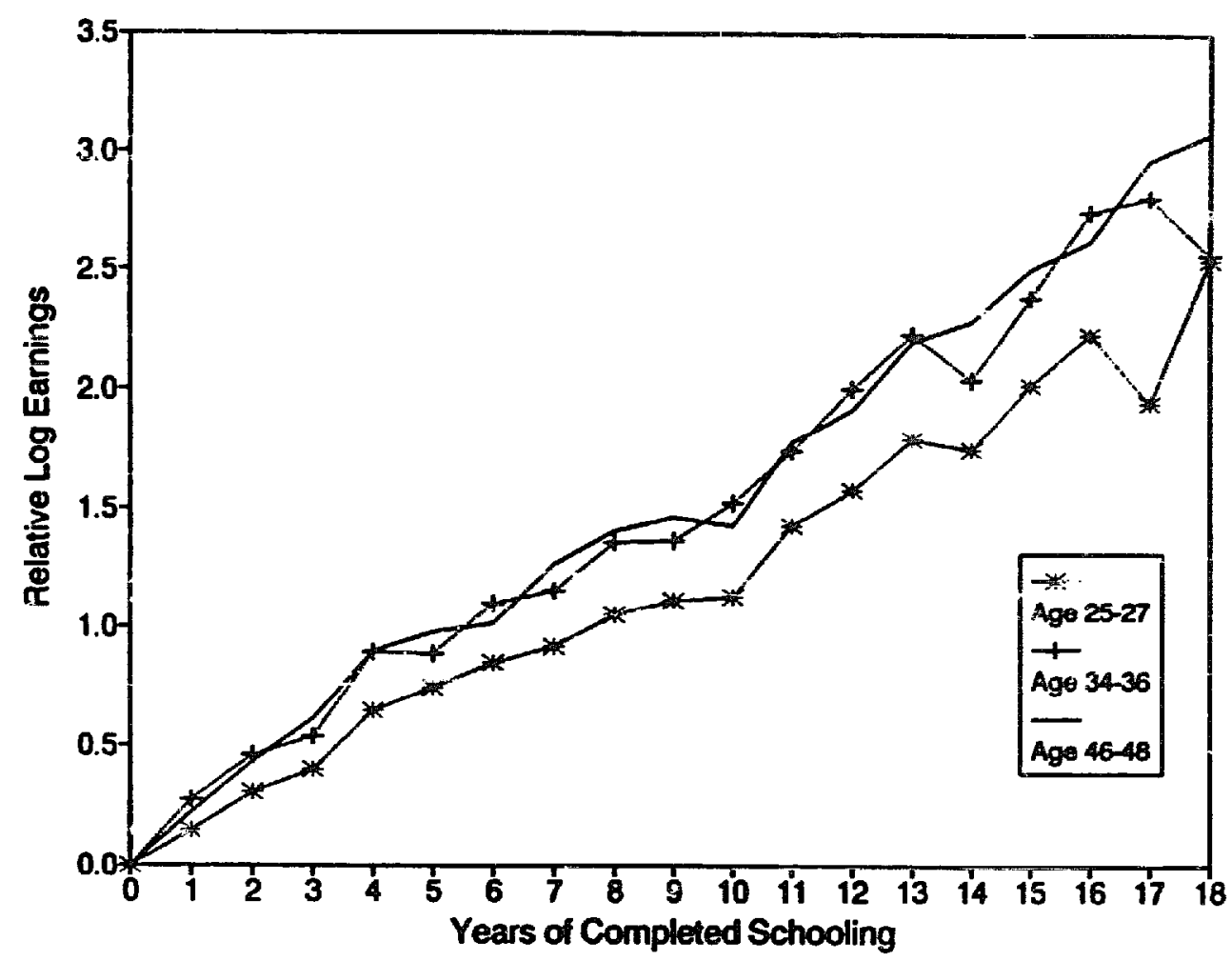

Fig. 8. OLS regressions using single year of completed schooling: Log earnings relative to males with zero years of completed schooling, three-year age groups, Brazilian males with positive earnings, PNAD 1985.

zero schooving. Given small cell sizes in some single year schooling categories, these non-parametric estimates for different age groups are surprisingly regular, and suggest a remarkably linear relationship between log earnings and schooling. As evidence of the reasonableness of the linear specification, we compared the $R^{2}$ for earnings regressions using a linear specification, a quadratic specification, and the non-parametric specification with $18 \mathrm{dum}$ mies. For the 34-36 year old age group, for example, these $R^{2}$ s are 0.478 , 0.479 , and 0.488 , respectively. Similar modest improvements in explanatory power by moving to a more flexible functional form are observed for all age groups. $^{20}$

As a final tesi of the sensitivity of our results we considered regional variations in the patterns documented above. Disparities across geographical regions and between urban and rural areas are often of primary importance

\footnotetext{
${ }^{20}$ Estimates of returns to schooling may be biased for a variety of reasons, such as omitted family background or ability. Behrman and Wolfe (1984), for example, conclude from evidence on sihlings in Nicaragua that estimates of returns to schooling are significantly overstated when family-related background characteristics are not controlled for. We see ne reason to expect systematic relationship between these potential biases and age or cohor, however.
} 
in empirical studies of inequality in Brazil. ${ }^{21}$ To answer questions about the overall level of inequidity in Brazil, our nationally representative sample is the appropriate level of analysis. Analysis by regions is, in effect, a study of within-region inequality, whereas we want to examine both within- and between-region variance in the distribution of earnings. A national sample also avoids the serious problem of internal migration, known to vary systematically with age, education, and earnings. Age groups within one region may give a poor representation, for example, of the schooling history of men born in that region.

Nonetheless, it is interesting to see whether the patterns we describe above hold within regions. Using the 1985 PNAD we generated results equivalent to tables 1 and 2 for two very different regions of Brazil, the Northeast and the Southeast, with further stratification for rural-urban location. ${ }^{22}$ We find changes in the distribution of schooling within the Northeast and Southeast similar to those for Brazil as a whole. We observe steady increases in mean schooling and steady declines in mean-adjusted schooling inequaiity over time for both rural and urban areas in both regions. We observe a peak in the variance of schooling similar to that for all of Brazil in the Southeast region overall and in Southeast urban areas. Northeast urban areas and the Northeast overall show patterns of rising, peaking, then falling variance, although the peaks arc for somcwhat ycunger cohorts than for Brazil as a whole. Rural areas in both regions have much lower variances in schooling, which tends to rise throughout the four decades. Estimates of age-specific earnings equations for rural and urban areas of the Southeast and Northeast indicate age profiles of inequality strikingly similar to those for Brazil as a whole. Within regions we find the same pattern of increasing returns to schooling with age as seen in fig. 7 for all Brazil. We also find that the pattern of increasing residual variance with age holds within these regions and their urban and rural areas. On the whole, the patterns in the age profiles of earnings inequality for all of Brazil appear quite robust across regions, in spite of the large differences in the cverall levels of schooling and earnings in these regions.

\section{Conclusions}

Analysis of three-year age groups from the 1985 PNAD indicates that cohorts of Brazilian males born in the four decades between 1925 and 1963 experienced steady increases in the mean level of schooling, with the mean doubling from the oldest cohorts to the youngest. This rising mean was associated with steady declincs in schooling inequality. The coefficient of

${ }^{21}$ See, for example, Almeida dos Reis and Barros (1989).

${ }^{22}$ See Lam and Levison (1989) for detailed analysis of these regional comparisons. 
variation in years of schooling declined for every successive cohort, falling by almost 50 percent from the oldest cohorts to the youngest. Lorenz curves for years of schooling demonstrate an unambiguous decline in mean-adjusted schooling inequality. The variance in years of schooling, a critical determinant of earnings inequality, increased for the first two decades of this period, reached a peak with the 1949-51 cohort, and has declined for all succeeding cohorts.

Estimates of separate earnings equations for three-year age groups in 1985 indicates that changes in the distribution of schooling in Brazil should in and of themselves have improved the distribution of labor earnings in Brazil beginning with cohorts born in the eariy 1950s. Earnings inequality falls dramatically from the 1946-48 cohort to the 1961-63 cohort, a pattern that is predicted by the declining variance in years of schooling over this period. Decomposition of the earnings equations reveals that two other factors play an important role in explaining this decline, however. Both returns to schooling and residual variance are higher for older cohorts, making inequality rise rapidly with age (i.e. fall with birth cohort). These two effects reinforce the effect of changes in the variance of scheoling on earnings inequality.

Comparison of age and cohort profiles of inequality for 1976, 1982, and 1985 show that earnings inequality in Brazil increased cver this period, in spite of the beneficial changes in the distribution of schooing. Our decomposition indicates that the contribution of schooling was in fact to improve the distribution from 1976 to 1985 , with declines in both the variance of schooling and in the returns to schooling. These improvements were more than offset, however, by increases in other sources of inequality. Although the increase from 1976 to 1985 in the variance of the component of earnings that is uncorrelated with schooling is disturbing, we believe that our results regarding the schooling component of inequality provide reason for optimism about the future of earnings inequality in Brazil. While residual variance is likely to be sensitive to short-run economic conditions, the dramatic improvements in the distribution of schooling we document represent fundamental changes in the determinants of earnings inequality in Brazil. Our results suggest that changes in the distribution of schooling in Brazil in recent decades have had beneficial effects on the distribution of income, effects that should continue to be seen for decades. The decline in the variance of schooling that began for males born around 1950 implies that new cohorts entering the labor market should experience lower earnings inequality at every age, with past improvements in the schooling distribution having an increasingly equalizing effect on overall earnings inequality as post-1950 birth cohorts become an increasing proportion of the labor force.

Evidence cited earlier suggests that Brazil's recent experience of both increasing mean schooling leveis and declining inequality $i_{i}$ schooling is not 
unique among developing countries. This suggests that our findings may have implications beyond Brazil. To the extent that educationai expansion in other developing countries reduces the variance in schooling variance, as appears to have occurred in Brazil, improvements in earnings inequality should result. If, in addition, there is a decline in returns to schooling, as also appears to have happened in Brazil, there will be further improvements in the distribution of earnings. Unfortunately, Brazil's recent experience also demonstrates that even substantial improvements in the schooling component of earnings inequality do not guarantee overall declines in inequality. Hopefuily these are short-run cyclical effects that will in the long-run be dominated by the structural improvements in the distribution of schooling.

\section{Appendix}

Table A.1

Distribution of earnings for three-year age groups - Brazilian males with positive earnings, 1976 and i 982 PÑNí."

\begin{tabular}{|c|c|c|c|c|c|c|c|c|c|c|}
\hline \multirow[b]{2}{*}{$\begin{array}{l}\text { Age } \\
\text { (1) }\end{array}$} & \multicolumn{5}{|c|}{1976 PNAD } & \multicolumn{5}{|c|}{1982 PNAD } \\
\hline & $\begin{array}{l}N \\
(2)\end{array}$ & $\begin{array}{l}V(\ln Y) \\
(3)\end{array}$ & $\begin{array}{l}\hat{\beta} \\
\text { (4) }\end{array}$ & $\begin{array}{l}R^{2} \\
(5)\end{array}$ & $\begin{array}{l}V(u) \\
(6)\end{array}$ & $\begin{array}{l}N \\
\text { (7) }\end{array}$ & $\begin{array}{l}V(\ln Y) \\
(8)\end{array}$ & $\begin{array}{l}\hat{\hat{\beta}} \\
(9)\end{array}$ & $\begin{array}{l}R^{2} \\
(10)\end{array}$ & $\begin{array}{l}V(u) \\
(11)\end{array}$ \\
\hline $22-24$ & 8,740 & 0.631 & 0.117 & 0.304 & 0.439 & 11,487 & 0.558 & 0.107 & 0.305 & 0.388 \\
\hline & 8,184 & 0.791 & 0.138 & 0.411 & 0.466 & 10,862 & 0.721 & 0.127 & 0.408 & 0.427 \\
\hline & 7,829 & 0.931 & 0.156 & 0.467 & 0.496 & 10,283 & 0.817 & 0.141 & 0.464 & 0.438 \\
\hline $31-3$ & 6,256 & 1.00 & 0.167 & 0.499 & 0.505 & & 0.936 & 0.153 & 0.508 & 0.460 \\
\hline & 6,356 & 0.953 & 0.167 & 0.425 & 0.548 & 8,246 & 1.017 & 0.156 & 0.515 & 0.493 \\
\hline $37-39$ & 5,730 & 0.970 & 0.165 & 0.433 & 0.550 & 7,262 & 1.014 & 0.160 & 0.504 & 0.503 \\
\hline $40-42$ & 5,563 & 1.007 & 0.170 & 0.434 & 0.570 & 7,066 & 1.020 & 0.167 & 0.490 & 0.521 \\
\hline $43-45$ & 4,735 & 1.032 & 0.174 & 0.437 & 0.581 & 5,991 & 1023 & 0.171 & 0.467 & 0.545 \\
\hline $46-48$ & 4,410 & $1.05 ?$ & 0.176 & 0.419 & 0.611 & 5,202 & 1.056 & 0.167 & 0.434 & 0.598 \\
\hline $49-51$ & 3,811 & 1.051 & 0.181 & 0.415 & 0.615 & 4,556 & 1.066 & 0.172 & 0.437 & 0.600 \\
\hline $52-54$ & 3,223 & 1.095 & 0.181 & 0.406 & 0.651 & 4,179 & 1.023 & 0.171 & 0.414 & 0.600 \\
\hline $55-57$ & 2,424 & 1.064 & 0.178 & 0.361 & 0.680 & 3,367 & 1.016 & 0.163 & 0.348 & 0.662 \\
\hline $58-60$ & 2,075 & 1.130 & 0.187 & 0.397 & 0.681 & 2,579 & 1.014 & 0.168 & 0.384 & 0.624 \\
\hline $22-60$ & 69,336 & 0.951 & 0.152 & 0.385 & 0.585 & 90,466 & 0.921 & 0.142 & 0.408 & 0.545 \\
\hline
\end{tabular}

aSee notes to table 2 .

\section{References}

Almeida dos Reis, José Guilherme and Ricardo Paes de Barros, 1989, Income inequality and the distribution of education: Regional differences in inequality (IPEA/INPES, Rio de Janeiro) Feb.

Atkinson, Anthony B., 1970, On the measurement of inequality, Journal of Economic Theory 2, $244-263$.

Becker, Gary S. and Barry R. Chiswick, 1966, Education and the distribution of earnings, American Economic Review 56, no. 2, 358-369.

Behrman, Jere R. and Barbara L. Wolfe, 1984, The socioeconomic impact of schooling in a developing country, Review of Economics and Statistics 66, no. 2, 296-303.

Chiswick, Barry, 1971, Earnings inequality and economic development, Quarterly Journal of Economics 85, no. 1, 21-39. 
Fishlow, Alber! 1972, Brazilian size distribution of income, Anierican Economic Review 62, no. $2,3 \overline{9} \mathbf{i}-4 \mathbf{i} \hat{0}$.

Jencks, Christopher et al., 1972, Inequality: A reassessment of the effect of iamily and schooling in America (Basic Books, New Yơrik).

Kakwani, Nanak C., 1980, Income inequality and poverty: Methods of estimation and policy applications (Oxford University Press, Oxford).

Knight, J.B. and R.H. Sabot, 1981, The returns to education: Increasing with experience or decreasing with expansion, Oxford Bulletin of Economics and Statistics 43, 51-71.

Knight, J.B. and R.H. Sabot, 1987, Educational expansion, governmental policy, and wage compression, Journal of Development Economics 26, no. 2, 201-221.

Lam, David, 1984, The variance of population characteristics in stable populations, with applications to the distribution of income, Population Studies 38, 117-127, March.

Lam, David, 1988, Lorenz curves, inequality, and social welfare under changing population composition, Journal of Policy Modeling, April.

Lam, David and Deborah Levison, 1989, Declining inequality in schooling in Brazil and its effects on inequality in earnings, Population Studies Center, Research Report No. 89-170 (University of Michigan, Ann Arbor, MI).

Lam, David and Deborah Levison, 1990, Age, experience, and schooling: Decomposing earnings inequality in the U.S. and Brazil, Pesquisa e Planejamento Econômico, forthcoming.

Lam, David and Guilherme Sedlacek, 1990, Women's education, female labor supply, and fertility decline in Brazil (University of Michigan, Ann Arbor, MI) Sept.

Langoni, Carios Geraldo, 1973, Distribuição da renda e desenvolvimento econotnico do Brasil (Editora Expressao e Cultura, Rio de Janeiro).

Langoni, Carlos Geraldo, 1977, Income distribution and economic development: The Brazilian case, in Michael D. Intriligator, ed., Frontiers of quantitative economics. Vol. B (NorthHolland, Amsterdam) 587-6616.

Marin, Alan and George Psacharopoulos, 1976, Schooling and income distribution, Review of Economics and Statistics 58, no. 3, 332-338.

Mincer, Jacob, 1974, Schooling, experience, and earnings (NBER, New York)

Morley, Samuel, 1981, The effect of changes in the population on several measures of income distribution, American Economic Review 71, no. 3, 285-294.

Paglin, Morton, 1975, The measurement and trend of inequality: A basic revision. American Zconomic Review 65, 598-609, Sept.

Psacharopoulos, George, 1981, Returns to education: An updated international comparison, Comparative Education 17, 321-341.

Psacharopoulos, George and Ana Maria Arriagada, 1986, The educational composition of the labor force: An international comparison, International Labor Review 125, no. 5, 561-574.

Ram, Rati, 1984, Population increase, economic growth, educat'onal inequality, and income distribution, Journal of Development Economics 14, 419-428.

Ram, Rati, 1990, Educational expansion and schooling inequality: International evidence and some implications, Review of Economics and Statistics 72, no 2, 266-273.

Schultz. T. Paul, 1975, Long-term change in personal incone distribution: Theoretical approaches, evidence, and explanations, in: Donald $M$. Levine ind Mary Jo Bane, eds., The 'inequality' controversy: Schooling and distributive justice (Basic Books, New York).

Schultz, T. Paul, 1988, Education investments and returns, in: H. Chenery and T.N. Srinivasan, eds., Handbook of Development Economics, Vol. 1 (North-Holland, Amsterdam).

Senna, José Júlio, 1976, Escolaridade, experiência no trabalho e salários no Brasil, Revista Brasileira de Economia 30, no. 2, 163-193.

Shorrocks, Anthony F., 1983, Ranking income distributions, Economica 50, 3-17.

Smith, James P. and Finis Welch, 1979, Inequality: Race differences in the distribution of earnings, International Economic Review 20, no. 2, 515-526.

Tilak, Jandhyala, B.G., 1989, Education and its relation to economic growth, povery, and income distribution: Past evidence and further analysis, World Banf: Discussion Paper. nn 46 (World Bank, Washington, DC).

Tinbergen, Jan, 1972, The impact of education on income distribution. Review of Income and Wealth io, 255-265.

Winegarden, Calvin R.. 1979, Schooling and income distribution: Eviduce from international data, Economica 46, 83-87. 